\title{
Onboard determination of fuel stability in plug-in hybrid diesel cars by dielectric relaxation spectroscopy
}

\author{
M. Eskiner ${ }^{1}$, F. Bär ${ }^{1}$, M. Rossner ${ }^{1}$, A. Munack ${ }^{2,3}$, J. Krahl',3 \\ ${ }^{1}$ University of Applied Sciences and Arts, Friedrich-Streib-Straße 2, 96450 Coburg, Germany \\ mustafa.eskiner@tac-coburg.com \\ 2 Thünen Institute of Agricultural Technology (TI), Bundesallee 50, 38116 Braunschweig, Germany \\ ${ }^{3}$ Fuels Joint Research Group, www.fuels-jrg.de
}

\begin{abstract}
A method based on dielectric relaxation spectroscopy (DRS) is introduced for determination of fuel quality of biodiesel containing fuels in plug-in hybrid electric vehicles (PHEV). Dielectric parameters such as the real and imaginary part of permittivity were recorded in a broad frequency range. As capacitive cell for determining the real and imaginary part of the permittivity, a small-sized interdigital capacitor was developed, which could be integrated into PHEV in the future. Especially in plug-in hybrid cars the storage time of fuel in the fuel tank is expected to be significantly longer than for cars with conventional combustion engines. Therefore the fuel long-term stability is of particular importance. By means of DRS, high-molecular oxidation products, such as oligomers from biodiesel that are considered as precursors for deposits can be detected easily.
\end{abstract}

Key words: dielectric relaxation spectroscopy, permittivity, plug-in hybrid electric vehicles, diesel fuel, biodiesel

\section{Motivation}

To decrease the dependency on fossil fuels the use of electric vehicles will be focused on by many automotive manufacturers. Electrical vehicles such as PHEVs are additionally equipped with a combustion engine which combines the advantages of an electrical vehicle and a conventional vehicle with combustion engine. Series-production PHEV equipped with diesel engines are already available in the market (e.g. Volkswagen XL1 or Volvo V60). In the future more diesel equipped PHEV will be available.

Today, a quota of biodiesel in fossil diesel fuel is established in several countries all over the world. Considering the transport sector in Germany, a biodiesel proportion of $\max .7 \% \mathrm{v} / \mathrm{v}$ in fossil diesel fuel is statutory [1]. Since 2015, the conversion to a climate quota to reduce greenhouse gas ( $\mathrm{GHG}$ ) emissions from biofuels is established. According to the German federal government a GHG reduction commitment of $3.5 \%$ (2015), 4.0\% (2017) and 6.0\% (2020) must be satisfied e.g. by fuel industry, traders etc. [2]. There are some facts of blending fossil diesel fuel with biodiesel: saving of fossil diesel fuels, independence of global energy suppliers - thus strengthening the local economy and the reduction of climate-affecting emissions - especially $\mathrm{CO}_{2}$. Works from [3] showed an improved GHG balance, when using biodiesel as fuel. In case of $100 \%$ rape seed oil methylester (RME), which is commonly used as a biodiesel admixture in fossil diesel fuels in Germany, $\mathrm{CO}_{2}$ savings amounts to $38 \%$. In fossil diesel fuel with $7 \%$ biodiesel proportion this would mean a saving potential of $2.63 \%$.

Early investigations on aged diesel fuel/biodiesel blends showed a certain tendency to form sediments, which can partly be considered as oligomers from biodiesel [4, 5]. Unsaturated fatty acid methylesters are especially responsible for this undesired fuel instability and lead significantly to the formation of sediments. Generally, unsaturated hydrocarbons undergo autoxidation forming alkyl and peroxy radicals [6,7], which can react with oxygen to form peroxides or hydroperoxides. These peroxides can lead to epoxides, which form acids, aldehydes, ketones or react with other alkyl and peroxy radicals to form dimers or oligomers [4].

In PHEV, the combustion engine is only used when the power supply from the battery is too low. On short distance rides, the combustion engine is not necessary, because of frequent battery recharging. Consequently, the storage time of the fuel in the tank is much longer than 
usual. Possible damages and problems due to aged fuels can occur at the fuel pump, injection systems or exhaust aftertreatment. Fuel pump and injection system are very sensitive to an increase in viscosity due to oligomerization. The increased viscosity leads to poorer nebulization during injection. This can lead to an increase of soot or unburned fuel in the exhaust gas aftertreatment system due to an incomplete combustion.

Generally, the oxidation stability describes the ability of a substance to withstand oxidative processes. If the oxidation stability of biofuels is exceeded, their aging begins and oligomers can occur. A common method for determining the oxidation stability of biodiesel or fossil diesel fuels blended with biodiesel is the Rancimat method according to DIN EN 15751. This is a laboratory test procedure where the measuring of increase in conductivity by acid formation during an accelerated aging process of biodiesel is determined.

The aim of our research was to determine the aging degree due to oligomers formed in biodiesel blends with suitable onboard sensors in PHEV. Such a sensor could be integrated in fuel tanks of PHEV where oligomers formed in the ageing process of the fuel should be detected at an early stage. Hence, damages of the engine should be avoided. The detection principle of the newly designed sensor is based on DRS.

\section{Theoretical Background}

Measurements of dielectric parameters in the frequency domain, the real- and imaginary part of the permittivity $\left(\varepsilon_{r}^{\prime}\right.$ and $\left.\varepsilon_{r}^{\prime \prime}\right)$ are determined by applying an alternating voltage between the electrodes at different frequencies. Inserting a dielectric material (e.g. liquid, solid) between electrodes leads to a decrease of the primary electrical field because of polarization mechanisms like displacement polarization, orientation polarization or interfacial polarization [8].

In atoms or non-polar molecules exposed to an electrical field, the displacement of the positive charge and negative charge concentrations, respectively, lead to an intramolecular electrical field, which is opposed to the primary electrical field. Consequently the displacement polarization leads to an attenuation of the primary electrical field. Orientation polarization describes the alignment of polar molecules in an electrical field. The ability to follow the changing of the applied electric fields depends on the frequency. Polar and high molecular compounds show at higher frequencies less ability to follow these alternating electric field because of inertia. This phenomenon is called dielectric relaxation. It is also clear that the orientation polarization is strongly dependent on the temperature which also influences the mobility of these molecules. After that, similar to the displacement polarization, adjusted molecules attenuate the primary electrical field. The interfacial polarization is noticeable at low frequencies. In this case, polar molecules acting as free charge carrier in the mixture are able to migrate to the capacitor plates and therefore conductivity mechanisms occur.

The polarization mechanism and consequently the decrease of the primary electrical field lead to an increase of the capacitance. Usually, the relative permittivity $\varepsilon_{r}^{\prime}(\omega, T)$ is defined as the quotient of the capacitance with a dielectric $C(\omega, T)$ and the capacitance of the empty cell, $C_{0}(\omega, T)$ (eq. 1 ), where $\omega$ is the angular frequency and $T$ the temperature: [9]

$\varepsilon_{r}^{\prime}(\omega, T)=\frac{C(\omega, T)}{C_{0}(\omega, T)}$

The permittivity is a complex valued function (eq. 2):

$\varepsilon_{r}(\omega, T)=\varepsilon_{r}^{\prime}(\omega, T)-i \varepsilon_{r}^{\prime \prime}(\omega, T)$

The meaning of the real part is already mentioned in (1). The imaginary part describes the dissipation caused by polarization mechanism and conductivity. Both, the alignment of polar molecules and motion of free charges in dielectrics lead to friction with vicinal molecules and thus to losses. In frequency ranges where relaxation occurs, a decrease of the real part and an increase of the imaginary part of the permittivity is observable. The imaginary part can be further subdivided into two terms (eq. 3) [10].

$\varepsilon_{r}^{\prime \prime}(\omega, T)=\varepsilon_{r, p o l}^{\prime \prime}(\omega, T)+\frac{\sigma}{\omega \varepsilon_{0}}$

$\varepsilon_{r, p o l}^{\prime \prime}(\omega, T)$ is associated with losses due to polarization, whereas the second term is directly proportional to conductivity $\sigma$ (e.g. due to free charge carriers). $\varepsilon_{0}$ is the permittivity constant of free space $\left(8.854^{*} 10^{-12} \mathrm{~F} / \mathrm{m}\right)$. The relationship between real and imaginary part of permittivity is as follows 
$\tan \delta=\frac{\varepsilon_{r}^{\prime \prime}(\omega, T)}{\varepsilon_{r}^{\prime}(\omega ; T)}$.

$\tan \delta$ is the so-called dissipation factor.

\section{Laboratory Test Setup}

The newly designed capacitive sensor is a printed circuit board with interdigital structure which is used to determine the dielectric parameters (Fig. 1). Similar sensor principles were also mentioned in $[11,12]$. To avoid interaction with fuels, the copper surface was coated with gold.

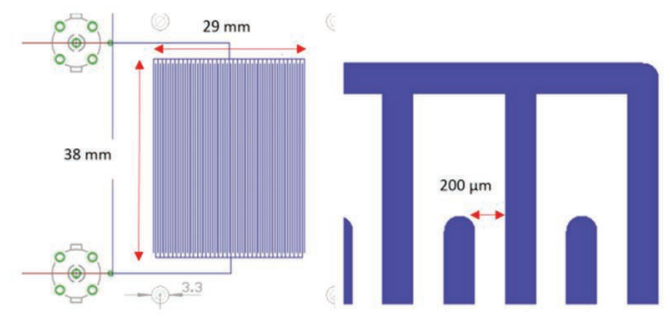

Fig. 1: Printed circuit board with interdigital structure (interdigital capacitor)

Fig. 2 shows the laboratory prototype with the integrated interdigital capacitor. The surface of the capacitive area can be covered with fuel. Since the permittivity has a strong dependency on temperature, a constant temperature control of the dielectric is necessary. For this reason, a Peltier element, which is fixed below the printed circuit board, a PT100 sensor and a cooler (for cooling down the Peltier element) are connected to a temperature control unit (Belektronig HAT control). In addition to a constant temperature control, this test setup allows also variation of the temperature in the range between 0 and $50{ }^{\circ} \mathrm{C}$. Below $0{ }^{\circ} \mathrm{C}$ condensed water from air humidity in the dielectric could cause distortion during permittivity measurement. The sensor is connected to an impedance analyzer (HP 4162a) that detects capacitance and dissipation factor $\tan \delta$. Knowing the capacitance of the empty cell (air) $C_{0}(\omega, T)$ and with dielectric $C(\omega, T), \quad \varepsilon_{r}^{\prime}(\omega, T)$ can be calculated from eq. 1. Afterwards, with eq. 4 the imaginary part can be calculated. For cleaning purposes, the electrodes can be easily washed (eg. isopropanol). Calibration was performed using isopropanol (VWR) as reference liquid.

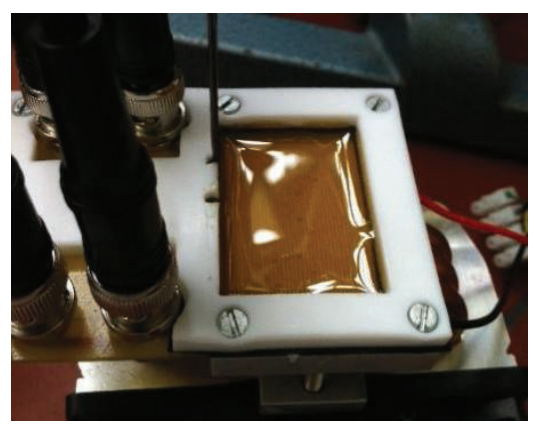

Fig. 2: Laboratory prototype

\section{Sample Preparation}

To determine the fuel stability, the alteration of dielectric parameters for fresh and aged biodiesel were measured in the frequency range of $2 \mathrm{kHz}$ to $13 \mathrm{MHz}$ and the temperature range between $10{ }^{\circ} \mathrm{C}$ and $50^{\circ} \mathrm{C}\left( \pm 0.1^{\circ} \mathrm{C}\right)$. The biodiesel used was RME without any additives, which was delivered by ADM, Hamburg, Germany. It was within the specification for biodiesel (DIN EN 14214:2003). Furthermore, seven biodiesel samples were aged with the Rancimat method according to DIN EN 15751 (110 ${ }^{\circ} \mathrm{C}$ and $10 \mathrm{~L} / \mathrm{h}$ air supply). Aged RME samples were taken after an aging duration of 2, 4, 6, 7, 8, 10 and 12 hours. For comparative purposes, a fresh RME sample was used with an induction time of 6.3 hours, measured with the Rancimat method.

\section{Size Exclusion Chromatography (SEC)}

Oligomers from aged RME were analyzed via SEC (Agilent 1260 Infinity Quaternary LC System) with refractive index detection (Agilent 1260 Infinity Refractive Index Detector). The separation was done with $3 \times 30 \mathrm{~cm}$ PSS SDV (particle size $5 \mu \mathrm{m}$ porosity; first column $50 \AA$; second column $100 \AA$; third column $1000 \AA$ ) columns.

Further parameters of the SEC were:

Temperature of RI detector and column: $45^{\circ} \mathrm{C}$ Injection volume: $100 \mu \mathrm{L}$

Concentration: $100 \mathrm{mg}$ analyte per $\mathrm{mL}$ THF

Flow rate: $0.5 \mathrm{~mL} / \mathrm{min}$

Mobile phase: Tetrahydrofuran (Applichem, GPC grade).

A calibration curve was performed with polyethylene glycol (Agilent PEG calibration kit Part No.: PL2070-0100), with molar masses between $196 \mathrm{Da}$ and $21300 \mathrm{Da}$. To verify the accuracy of the GPC system, an analytical standard of methyl oleate (Fluka) was measured. With PEG as calibration, the molar mass of methyl oleate was determined to about 
$375 \mathrm{Da}$, while the real molar mass of methyl oleate is $296.45 \mathrm{Da}$. In order to make quantitative statements with regard to the molecule size, calibration standards and analytes must be identical. However, since precise oligomer structures are not known so far, an accurate calibration could not be performed.

\section{Results}

\section{Permittivity measurements at $10^{\circ} \mathrm{C}$}

Figure 3 shows the real and imaginary part of permittivity for fresh $(0 \mathrm{~h})$ and aged $(12 \mathrm{~h}) \mathrm{RME}$ at $10{ }^{\circ} \mathrm{C}$. For fresh RME no frequency dependency was observed in the frequency range between 2 and $3000 \mathrm{kHz}\left(\mathcal{E}_{r}^{\prime}=3.32\right.$ \pm 0.02 ). Only marginal dissipation could be observed for fresh RME ( $\varepsilon_{r}=0.005 \pm 0.003$ ). Probable relaxation is caused by methylester and natural antioxidants present in RME, which are visible in the range between 3 and $13 \mathrm{MHz}$. In this range, the real part of the permittivity is decreasing (3.058 \pm 0.001$)$, whereas the imaginary part is increasing (0.098 \pm 0.001$)$. Real part of permittivity shows a clear increase for aged RME (12 h) - most probably due to polar oxidation products (low- and highmolecular). In the frequency range between 2 $\mathrm{kHz}$ and $2 \mathrm{MHz}, \varepsilon_{r}^{\prime}$ is $4.90 \pm 0.07$. Above $2 \mathrm{MHz}$ a clear decrease for the real part of permittivity is observable $(4.220 \pm 0.005)$ due to the relaxation process of high-molecular oxidation products (oligomers). In comparison to the real part of the permittivity, the imaginary part of the permittivity is more suitable for the detection of oligomers, because it is more sensitive [13]. Here, the imaginary part is already increasing at $50 \mathrm{kHz}$ from $0.005( \pm 0.001)$ to $0.295( \pm 0.009)$ at $13 \mathrm{MHz}$. According to eq. 3, conductivity losses are observable in the low frequency range. At 2 $\mathrm{kHz}$ the imaginary part of the permittivity for fresh RME is $0.004( \pm 0.001)$. After an aging duration of 12 hours the imaginary part increases to $0.025( \pm 0.009)$.

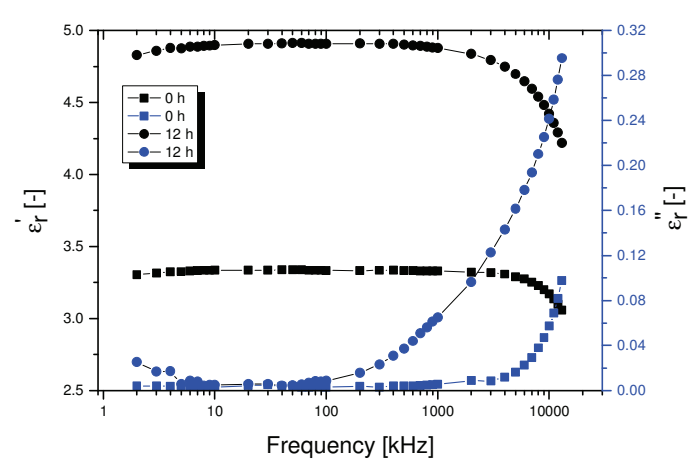

Fig. 3: Permittivity measurements for fresh $(0 \mathrm{~h})$ and aged (12 h) $R M E$ at $10^{\circ} \mathrm{C}$

\section{SEC measurements}

Figure 4 shows SEC measurements for all tested RME samples ( $0-12$ hours). The molar mass ranges between 350 and $425 \mathrm{~g} / \mathrm{mol}$ are those from fatty acid methylesters of the RME. For fresh RME an unexpected peak occurs in the higher molar mass range (about $740 \mathrm{~g} / \mathrm{mol}$ ). It is probably caused by glycerides as residual products of an incomplete transesterification reaction during the biodiesel production. The decrease of the RME peak during aging is associated with an increase of the oligomer range (>425 g/mol) due to its reaction to highmolecular oxidation products. The results indicate that in reference to their molar masses there were no preferable oligomers produced during the aging process. Hence, it is difficult to detect a valid peak maximum with increasing aging time. The highest detectable molar mass was about $1600 \mathrm{~g} / \mathrm{mol}$ after an aging duration of 12 hours.

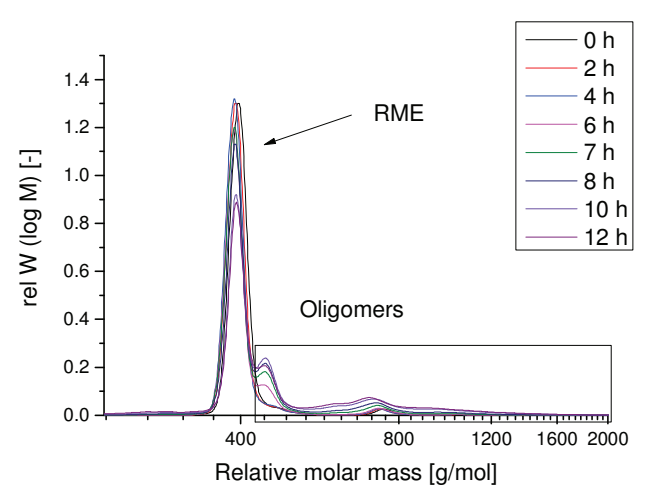

Fig. 4 Molar mass distribution for fresh and aged (012 h) RME measured by SEC 
Comparison of the imaginary part of permittivity $\left(10^{\circ} \mathrm{C}\right)$ and SEC

Due to its higher sensitivity, in the following only the imaginary part of permittivity will be discussed. Therefore, Figure 5 shows the imaginary part of the permittivity $(100 \mathrm{kHz}-13$ $\mathrm{MHz})$ for all investigated samples $(0-12 \mathrm{~h})$. The results for the fresh $(0 \mathrm{~h})$ and aged RME (12 h) samples were already discussed at Figure 2. Significant effect occurs for samples after an aging duration of 7 hours. Until an aging duration of 7 hours $(0-7 h)$ the imaginary part of permittivity is about 0.111 $( \pm 0.02)$ at $13 \mathrm{MHz}$. After 8 hours it increases to $0.206( \pm 0.042)$.

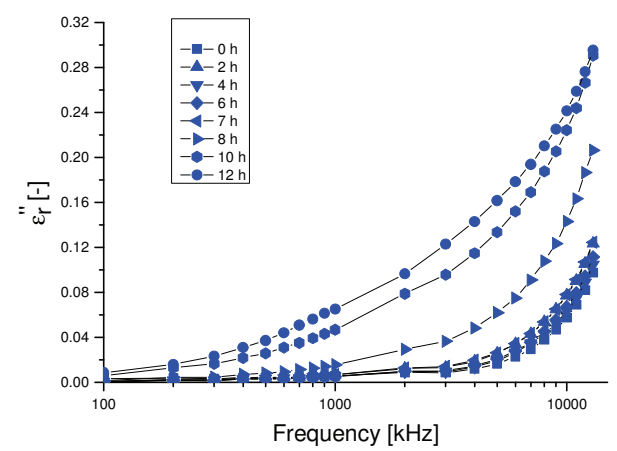

Fig. 5. High frequency range $(100 \mathrm{kHz}-13 \mathrm{MHz})$ of imaginary part of permittivity at $10^{\circ} \mathrm{C}$ for fresh and aged RME $(0-12 h)$

In Figure 6 the increase of the integrated area of the oligomer range (425 to $1600 \mathrm{~g} / \mathrm{mol}$ ) from SEC measurements (see also Fig. 4) is compared with the increase of the imaginary part of permittivity at $13 \mathrm{MHz}$ and $10{ }^{\circ} \mathrm{C}$ (see also Fig. 5). Using an intersection of tangents applied to both curves an induction time of 6.7 hours for both curves was found.

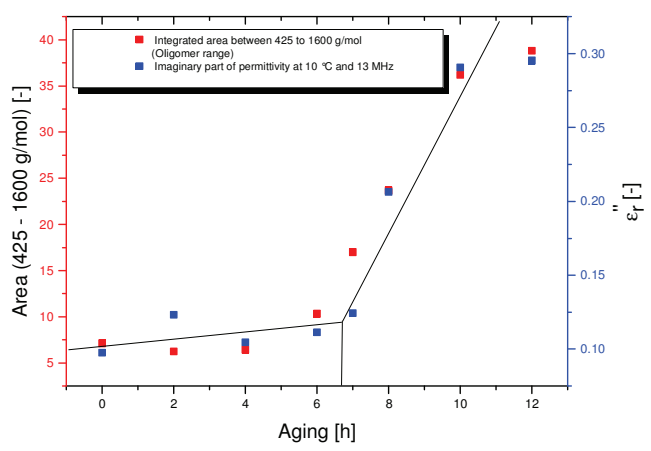

Fig. 6: Comparison of oligomer formation with SEC (integrated area between 425 and $1600 \mathrm{~g} / \mathrm{mol}$ ) and permittivity measurements $\left(13 \mathrm{MHz}\right.$ and $\left.10^{\circ} \mathrm{C}\right)$
As already discussed in Figure 3, the low frequency range of the imaginary part of permittivity is dominated by conductivity losses present in aged RME. An enhanced conductivity is observable when temperature is increasing due to lower viscosity and thus higher mobility of ions. For aged RME (12 h) the imaginary part of permittivity was 0.025 $( \pm 0.009)$ at $10^{\circ} \mathrm{C}$ and $2 \mathrm{kHz}$ (see also Fig. 3). In comparison to that the imaginary part of permittivity is now $0.159 \pm 0.006$ at $50{ }^{\circ} \mathrm{C}$ and 2 kHz (Fig. 7).

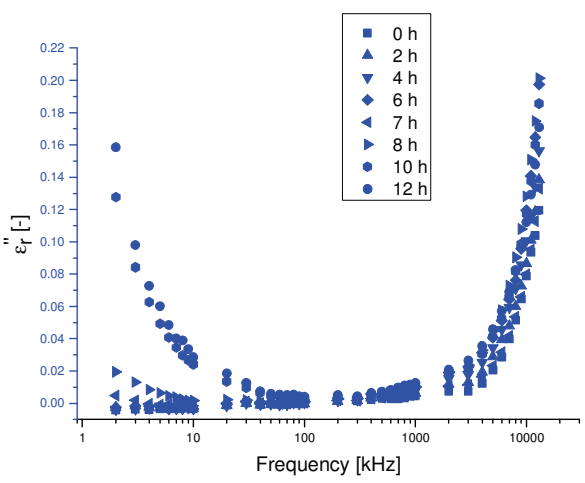

Fig. 7: Imaginary part of permittivity at $50{ }^{\circ} \mathrm{C}$

The increase of the imaginary part of the permittivity measurements $\left(50{ }^{\circ} \mathrm{C}\right.$ and $2 \mathrm{kHz}$ ) is compared to the increase of conductivity measured with the Rancimat method (Fig. 8). Via Rancimat an induction time of 6.3 hours was measured. Using an intersection of tangents applied to the imaginary part curve an induction time of $7.1 \mathrm{~h}$ is observable. Thus, DRS results slightly deviate from the Rancimat induction time. As mentioned before, the samples used in the permittivity measurements were aged with the Rancimat method. The outcome of this is that these samples are without volatile low-molecular carboxylic acids that enter the conductivity measuring cell of the Rancimat. Consequently, only those oxidation products, which could not escape in the original sample were measured by means of DRS. According to $[14,15]$, losses in the low frequency range are caused due to proton transfer from one hydroxyl oxygen to another. Considering the oxidation products in RME, which were found in $[4,5]$, this could be, on one hand, low-molecular oxidation products like aldehydes, ketones, carboxyl acids and, on the other hand, high-molecular oxidation products like peroxides, hydroperoxides and oligomers.

Permittivity measurements at $50^{\circ} \mathrm{C}$ 


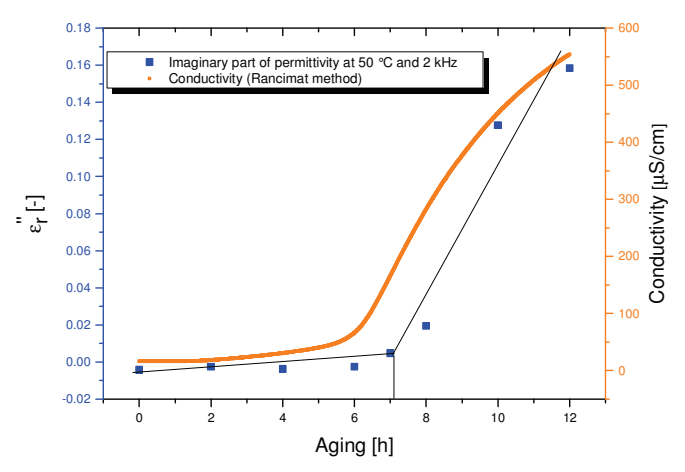

Fig. 8: Comparison of conductivity increase (Rancimat method) and increase of the imaginary part of the permittivity at $50^{\circ} \mathrm{C}$ and $2 \mathrm{kHz}$

\section{Conclusion}

By means of DRS, it is possible to detect oxidation products in aged biodiesel. As a capacity cell for DRS measurements a printed circuit board with interdigital structure (interdigital capacitor) was developed. The results showed that the imaginary part of permittivity is suitable to detect oligomers in the high frequency range due to dielectric relaxation. Oligomers are considered as precursors of undesired deposits and therefore their determination enables a fuel quality control. Furthermore a good correlation with the standard test procedure for oxidation stability measurements via the Rancimat method (DIN EN 15751) is shown in the low frequency range. The small size of the newly developed interdigital capacity sensor is an option for onboard control in PHEV. In the long term, the sensor prevents engine damages since fuel degradation is detectable at an early stage and the combustion engine can be started before precipitations occur. In this way, the sensor enables the future use of commonly used diesel fuel even in plug-in hybrid diesel vehicles. So the DRS sensor supports and enables electromobility.

\section{References}

[1] DIN EN 590:2014-04, Kraftstoffe für Kraftfahrzeuge - Dieselkraftstoff - Anforderungen und Prüfverfahren, (2014)

[2] Gesetz zum Schutz vor schädlichen Umwelteinwirkungen durch Luftverunreinigungen, Geräusche, Erschütterungen und ähnliche Vorgänge (Bundes-Immissionsschutzgesetz BimSchG), 20.11.2014, (2014)
[3] Union zur Förderung von Oel- und Proteinpflanzen (UFOP), Erneuerbaren-EnergienRichtlinie RED Biokraftstoffnachhaltigkeitsverordnung Klimaschutzquote - NUTS2 - THG-Werte, (2013)

[4] H. L. Fang, R. L. McCormick, Spectroscopic Study of Biodiesel Degradation Pathways, SAE Technical Paper Series 2006-01-3300, (2006)

[5] L. Schmidt, Wechselwirkungen zwischen Kraftstoffkomponenten und biodieselbasierten Mischkraftstoffen unter besonderer Berücksichtigung der Alterungsprodukte von Fettsäuremethylestern, Cuvillier Verlag, ISBN: 978-3-95404-667-6, Göttingen, (2014)

[6] W. J. Bartz, Additive für Schmierstoffe, ExpertVerl., Renningen-Malmsheim, ISBN: 3-81690916-7, (1994)

[7] R. M. Mortier, M. F. Fox, S. T. Orszulik, Chemistry and technology of lubricants, Springer, New York, ISBN: 978-1-4020-8661-8, (2010)

[8] A. R. von Hippel, Dielectric materials and applications, Artech House, Boston, ISBN: 9781580531238, (1995)

[9] V. Crastan, Elektrische Energieversorgung, Springer, Berlin, ISBN: 978-3642198557, (2007)

[10] S. Romano, P. Sorichetti, Dielectric Spectroscopy in Biodiesel Production and Characterization Springer, ISBN: 978-1849965187, (2010)

[11] M. Golio, The RF and Microwave Handbook, ISBN: 978-0849385926, (2001)

[12] A. S. Zolfakar, A. Shah, N. H., Mahzan, A. Manut, M. F. Idros, Design, fabrication and characterization of $\mathrm{pH}$ transducer using printed circuit board (PCB), Electronic Devices, Systems and Applications (ICEDSA), 2010 International Conference on Electronic Devices, Systems and Applications, Kuala Lumpur, (2010)

[13] C. J. Collister, Electrical measurement of oil quality, Patent US 6459995 B1, (1998)

[14] J. D. Hoffman, C. P. Smyth, Molecular Rotation in the Solid Forms of Some Long-Chain Alcohols, Journal of the American Chemical Society, Vol. $71,(1949)$

[15] Y. Kakiuchi, H. Komatsu, S. Kyoya, Spectroscopic Evidence for the Proton Conductivity through Solid Alcohols, Journal of Chemical Physics, Vol. 19, (1951) 